\title{
A HIGHLY DISCRIMINATORY MULTI-TYPING SCHEME FOR PROTEUS MIRABILIS AND PROTEUS VULGARIS
}

\author{
B. W. SEnior and P. Larsson*
}

Department of Bacteriology, The University of Dundee Medical School, Ninewells Hospital, Dundee DD1 9SY, Scotland and *Departments of Clinical Bacteriology and Clinical Immunology, Institute of Medical Microbiology, University of Gothenburg, S-413 46 Göteborg, Sweden.

Summary. Strains of Proteus mirabilis and $P$. vulgaris isolated in England, Scotland and Sweden were characterised by proticine production-proticine sensitivity (P-S) typing, $O$ serotyping and Dienes typing methods. The determinants of $\mathrm{O}$ antigenicity were independent of those determining proticine production and proticine sensitivity. Because of this independence, the combination of P-S typing and $\mathrm{O}$ serotyping for the analysis of the 133 serotypable strains separated them into 81 distinct types whereas $\mathrm{P}-\mathrm{S}$ typing and $\mathrm{O}$ serotyping methods alone separated them into only 56 and 19 types respectively. There was a relationship between the Dienes type and the P-S type; the determinants of Dienes compatibility were the proticine production-proticine sensitivity characters. The determinants of $\mathrm{O}$ antigenicity appeared to play no role in the Dienes reaction. Some strains that were indistinguishable by $\mathrm{P}-\mathrm{S}$ typing and $\mathrm{O}$ serotyping methods were distinguished by Dienes typing.

\section{INTRODUCTION}

Infections of the urinary tract with Proteus spp. are common, particularly in young boys (Bergström, 1972; Hallett, Pead and Maskell, 1976) and the elderly (Walkey et al., 1967; Senior, 1979). It is important that these infections are diagnosed rapidly and cured, because it has been suggested that Proteus spp. have a special predilection for the upper urinary tract (Fairley et al., 1971). As a result of urease activity (Senior, Bradford and Simpson, 1980) the urine rapidly becomes alkaline. This leads to necrosis of the renal tubular epithelium (Braude, Siemienski and Shapiro, 1960) and the formation of renal stones (Griffith, Musher and Campbell, 1973).

Recurrent urinary tract infections with Proteus spp. may arise either by re-infection with a new and different Proteus strain or by relapse because of failure to eliminate the original infecting strain. In order to determine which is the case in a specific patient, and for the epidemiological tracing of nosocomial strains, highly specific typing schemes for Proteus spp. are needed. Several techniques have been described (Tracy 
and Thomson, 1972; Kashbur, George and Ayliffe, 1974; Schmidt and Jeffries, 1974), but few have come into widespread use. Serotyping of Proteus spp. is useful for characterising strains of epidemiological interest (Lányi, 1956; de Louvois, 1969; Larsson, Andersson and Norlen, 1978) but certain combinations of $\mathrm{O}$ and $\mathrm{H}$ antigens can be common and some strains require additional typing procedures.

Serotyping permits identification of $49 \mathrm{O}$ antigens and $19 \mathrm{H}$ antigens among strains of P. mirabilis and P. vulgaris (Perch, 1948; Kauffmann, 1969). Some additional provisional serotypes have also been reported (Larsson and Olling, 1977; Penner and Hennessy, 1980). The proticine production-proticine sensitivity (P-S) typing method of Senior (1977a) enabled 250 Proteus strains to be separated into 90 P-S types. The Dienes typing of 204 swarming strains of Proteus in all combinations resulted in the description of 98 distinct Dienes compatibility types (Senior, 1977b).

The aim of this study was to investigate whether these typing schemes were independent of each other so that a combination of the three schemes might permit finer discrimination between strains than is possible by any one typing scheme alone.

\section{MATERIALS AND MethodS}

Bacterial strains. The 169 strains of Proteus examined were isolated in England (Portsmouth), Scotland (Dundee) and Sweden (Gothenburg) and were maintained as pure cultures either on nutrient agar slopes at $4^{\circ} \mathrm{C}$ or in deep agar stab cultures at room temperature. Each strain was identified from the results of reactions in glucose, lactose, mannitol and maltose peptone-water-sugar cultures and tests for ornithine decarboxylase and indole formation: 161 strains gave reactions typical of $P$. mirabilis and eight strains gave reactions typical of $P$. vulgaris. The 100 strains from Sweden ( 97 P. mirabilis and three $P$. vulgaris) consisted of 55 isolates from urine and $\mathbf{4 5}$ from faeces selected to represent 10 common $\mathrm{O}$ serotypes of Proteus, as well as non-agglutinating and spontaneously agglutinating strains. The urinary strains were isolated from patients with significant bacteriuria $\left(\geqslant 10^{5}\right.$ organisms $/ \mathrm{ml}$.) and the faecal strains were from healthy individuals. The 48 English strains ( 45 P. mirabilis and three P. vulgaris) were isolated from the urine of young boys with urinary tract infections. Each strain was present as a pure growth in freshly voided urine in numbers greater than $10^{5} / \mathrm{ml}$. The 21 Scottish strains $(19 P$. mirabilis and two $P$. vulgaris) were selected to represent eight proticine production-proticine sensitivity (P-S) types found commonly among typical urinary types and typical faecal types of Proteus (Senior, 1979). Twelve of the strains were isolated from patients with urinary tract infections and nine strains were isolated from the faeces of different people without urinary tract infection. Only one isolate from each patient or subject was included in the study.

$O$ serotyping. Proteus $\mathrm{O}$ serotyping was performed as previously described (Larsson and Olling, 1977). Briefly, an overnight nutrient broth culture of each strain was autoclaved for 30 min. One drop of this suspension was mixed with one drop of diluted monovalent $\mathrm{O}$ antiserum (final dilution 1 in 800-1 in 1600) in wells of Perspex agglutination trays. Agglutinations were read with a plate microscope $(\times 12.5)$ after incubation overnight at $50^{\circ} \mathrm{C}$. Monovalent $\mathrm{O}$ antisera were available against the following $O$ antigens: $1,3-17,19,20,23-33,35,36,38,40,41$, 44, 49 and provisional $O$ antigens $A-E$.

Proticine production and proticine sensitivity (P-S) typing. Each strain was tested for the ability to produce a Proteus bacteriocine (proticine) - $\mathrm{P}$ type-and also for sensitivity to different proticines - $\mathrm{S}$ type - when tested against the standard set of proticine producers and indicator strains previously described (Senior, 1977a). The strains were typed by cross streaking young cultures on $1 \%(\mathrm{w} / \mathrm{v})$ Proteose Peptone No. 3 agar (Difco) containing $\mathrm{NaCl} 0.5 \%(\mathrm{w} / \mathrm{v})$ and $0.2 \mathrm{~mm}$ p-nitrophenyl glycerol (PNPG) -an anti-swarming agent without effect on P-S typing (Senior, 1977b).

Dienes typing. For each strain, a loopful of culture was applied to the surface of dried blood agar plates (Oxoid CM55 Blood Agar Base with 5\%(v/v) horse blood). Inocula were arranged (Senior, $1977 b$ ) so that the Dienes compatibility of each member of a set of strains could be 
tested simultaneously against each other member of the set. The plates were incubated at $30^{\circ} \mathrm{C}$ for $18 \mathrm{~h}$, or longer if necessary, and examined with reflected light for the presence of Dienes lines of inhibited or partially inhibited growth where the spreading haloes of growth of incompatible strains met. The swarming growths of strains of the same Dienes type were compatible and swarmed into one another without the formation of a Dienes line. Care was needed in reading the plates, because if a non-spreading strain was over-run by a spreading neighbouring strain and this was not recognised, the reaction would be wrongly interpreted as indicating compatibility.

\section{RESULTS}

All of the 169 strains were independently O serotyped and P-S typed; 190 serotypes and 56 P-S types were identified among 133 strains. Of the remaining 36 strains, 21 agglutinated spontaneously in saline and 15 were not agglutinated by any of the $41 \mathrm{O}$ sera tested; amongst these, nine P-S types not found among the $O$ agglutinating strains were found. The 100 Swedish strains of 10 serotypes, together with non-agglutinating and spontaneously agglutinating strains, belonged to $46 \mathrm{P}-\mathrm{S}$ types. Amongst the 21 Scottish strains of eight common P-S types were found representatives of 10 serotypes. The 48 English strains were of 30 P-S types and 14 serotypes.

Standard proticines were produced by $122(72 \%)$ of the strains. The commonest proticine producers were those that produced proticines 1, 5, 3 and 2 which were formed by $29(17 \%), 22(13 \%), 18(10.5 \%)$ and $15(9 \%)$ respectively of the strains (table I). None of the strains in this study produced proticines 11 or 13 . Generally, several $\mathrm{O}$ serotypes, usually in proportion to the number of strains, were found amongst the producers of a given proticine (table I).

Amongst the 133 serotypable strains, $91(68 \%)$ were sensitive to one or more of the standard proticines. Several $O$ serotypes, usually in proportion to the number of strains, were found amongst the strains of a given proticine sensitivity type (table II).

\section{TABLE I}

The frequency of different types of proticine-producing strains and the number of $O$ serotypes found amongst the $O$-serotypable strains

\begin{tabular}{|c|c|c|c|}
\hline $\begin{array}{l}\text { Proticine }(P) \text { type* } \\
\text { of producer } \\
\text { strain }\end{array}$ & $\begin{array}{c}\text { Number (percentage) } \\
\text { of producer } \\
\text { strains }\end{array}$ & $\begin{array}{c}\text { Number of } \\
\text { O-serotypable } \\
\text { producer strains }\end{array}$ & $\begin{array}{l}\text { Number of serotypes } \\
\text { amongst the O-serotypable } \\
\text { producer strains }\end{array}$ \\
\hline 0 & $47(28)$ & 33 & 15 \\
\hline 1 & 29 (17) & 25 & 7 \\
\hline 2 & $15(9)$ & 14 & 4 \\
\hline 3 & $18(10 \cdot 5)$ & 15 & 7 \\
\hline 4 & $6(3 \cdot 5)$ & 2 & 2 \\
\hline 5 & $22(13)$ & 18 & 5 \\
\hline 6 & $12(7)$ & 10 & 3 \\
\hline 7 & $6(3 \cdot 5)$ & 3 & 2 \\
\hline 8 & $1(0 \cdot 6)$ & 1 & 1 \\
\hline 9 & $5(3)$ & 5 & 2 \\
\hline 10 & $1(0 \cdot 6)$ & 1 & 1 \\
\hline 12 & $7(4 \cdot 1)$ & 6 & 5 \\
\hline Total & $169(100)$ & 133 & 54 \\
\hline
\end{tabular}

* See Senior $(1977 a)$; type $0=$ proticine not produced. 


\section{TABLE II}

The frequency of different combinations of proticine-sensitivity and the number of $O$ serotypes found amongst 1330 -serotypable strains

\begin{tabular}{ccc}
\hline $\begin{array}{c}\text { Proticine-sensitivity } \\
\text { (S) type* of strain }\end{array}$ & $\begin{array}{c}\text { Number of O-serotypable } \\
\text { strains of the S type }\end{array}$ & $\begin{array}{c}\text { Number of } \\
\text { O serotypes found }\end{array}$ \\
\hline 0 & 42 & 9 \\
1 & 16 & 4 \\
1,5 & 3 & 3 \\
1,8 & 8 & 3 \\
$1,8,13$ & 2 & 1 \\
1,13 & 2 & 1 \\
2 & 1 & 1 \\
2,3 & 1 & 1 \\
2,11 & 1 & 1 \\
3 & 1 & 1 \\
3,9 & 1 & 1 \\
4 & 8 & 5 \\
4,12 & 4 & 1 \\
5 & 8 & 6 \\
5,12 & 1 & 1 \\
6 & 1 & 1 \\
6,11 & 1 & 1 \\
7 & 13 & 5 \\
7,12 & 1 & 1 \\
8 & 1 & 1 \\
9 & 8 & 4 \\
10 & 2 & 2 \\
11 & 6 & 5 \\
12 & 1 & 1 \\
\hline
\end{tabular}

* See Senior (1977a); type $0=$ not sensitive to any proticine.

A full cross-match analysis of P-S type and O serotype of the serotypable strains is presented in table III. These results show that the characteristics that determined the $\mathrm{P}-\mathrm{S}$ type of a strain were independent of those that determined the $\mathrm{O}$ serotype. Thus, regardless of the origin of strains, those of a given $\mathrm{P}-\mathrm{S}$ type could belong to different $\mathrm{O}$ serotypes and those of a given $O$ serotype could include representatives of several P-S types. The independence of the P-S typing scheme from the $O$ serotyping scheme meant that a combination of the results of the two schemes gave greater discrimination between strains than either scheme alone. The 133 strains typable by both methods could be separated into 81 types.

Because Dienes reactions of compatibility are given only by strains of the same P-S type (Senior, 1977b) predictions were made and tested of the inter-relationship between P-S type, O serotype and Dienes type. For example, it was predicted that strains of the same P-S type and same O serotype would show Dienes reactions of compatibility with each other. In all of the 30 Dienes tests performed on strains representing seven combinations of $\mathrm{O}$ serotype and $\mathrm{P}-\mathrm{S}$ type, the predictions were found to be correct.

The possibility of a relationship between Dienes type and $O$ serotype was examined by testing the Dienes compatibility of strains of the same $O$ serogroup but of different P-S types. Amongst the Swedish strains examined were six strains of serotype O3, three strains of serotype O10, four strains of serotype O13-30, six strains of serotype $\mathrm{O} 28$ and four strains of serotype O30. All strains of the same O serotype but of 
different P-S types were incompatible with one another. This indicates that the determinants of Dienes compatibility are independent of the determinants of $O$ antigenicity.

On the basis of this result and the independence of P-S type and O serotype, it was predicted that amongst Dienes-compatible strains of the same P-S type, some should be of the same serotype whereas others should be of different serotypes. Again, these predictions were found to be correct, confirming the validity of the conclusions drawn from the results.

If the determinants of Dienes compatibility are independent of the O serotype of a strain and are determined by the P-S characters, strains of the same P-S type but of different $O$ serotypes should be compatible with each other. This prediction was tested, wherever possible, with strains representative of the three geographical regions. The results, presented in table IV, show that the prediction was generally correct. In a few instances, however, strains that were indistinguishable serologically and appeared to be of the same P-S type were of different Dienes types. Dienes typing was found to be most useful with these strains because it permitted distinction between strains that the other typing methods had failed to separate.

\section{Discussion}

The combination of three typing methods permitted fine discrimination between $P$. mirabilis and $P$. vulgaris strains from different countries. When 133 strains were typed by $O$ serotyping alone, 19 types were found. When these strains were typed by P-S typing alone, 56 types were found. However, when the strains were typed by both P-S typing and $O$ serotyping, 81 types were found and even more types could be distinguished if the strains were also Dienes typed.

Because colicines $\mathrm{A}, \mathrm{K}$ and $\mathrm{V}$ are intimately associated with the $\mathrm{O}$ antigen of the producing strain (Goebel and Barry, 1958; Hutton and Goebel, 1962; Barry et al., 1965) and bacteriocine receptors are located on the outer surface of the bacterial cell, it was possible that a particular P-S type might have been associated with a particular $O$ serotype. However, this was not found to be the case. Apart from a few clusters of several representatives of a particular P-S type in one serotype, no association was found between $O$ serotype and either production of a particular proticine or sensitivity to proticine(s). The clusters of strains are thought to be repeated isolations of the same strain included by the selection of individuals who, by chance, had all been infected with the same strain. Moreover, the fact that P-S types were found amongst spontaneously agglutinating (rough) strains also lends support to the view that P-S types are not associated with the $\mathrm{O}$ side chain of the bacterial cell wall. Because the P-S typing method is based on characteristics that are independent of those that determine $\mathrm{O}$ antigenicity, the two typing methods can be used together to provide greater strain discrimination than either method alone can provide.

In a previous survey of Scottish isolates, proticine 3-producing strains were found frequently and were associated with patients who had severe urinary tract infections (Senior, 1979). The frequency of occurrence of the different proticine-producers amongst the English and Swedish strains was similar to that found amongst the Scottish strains in an earlier survey (Senior, 1977a). It is unlikely, therefore, that the observed proticine 3-virulence association was a local phenomenon. 


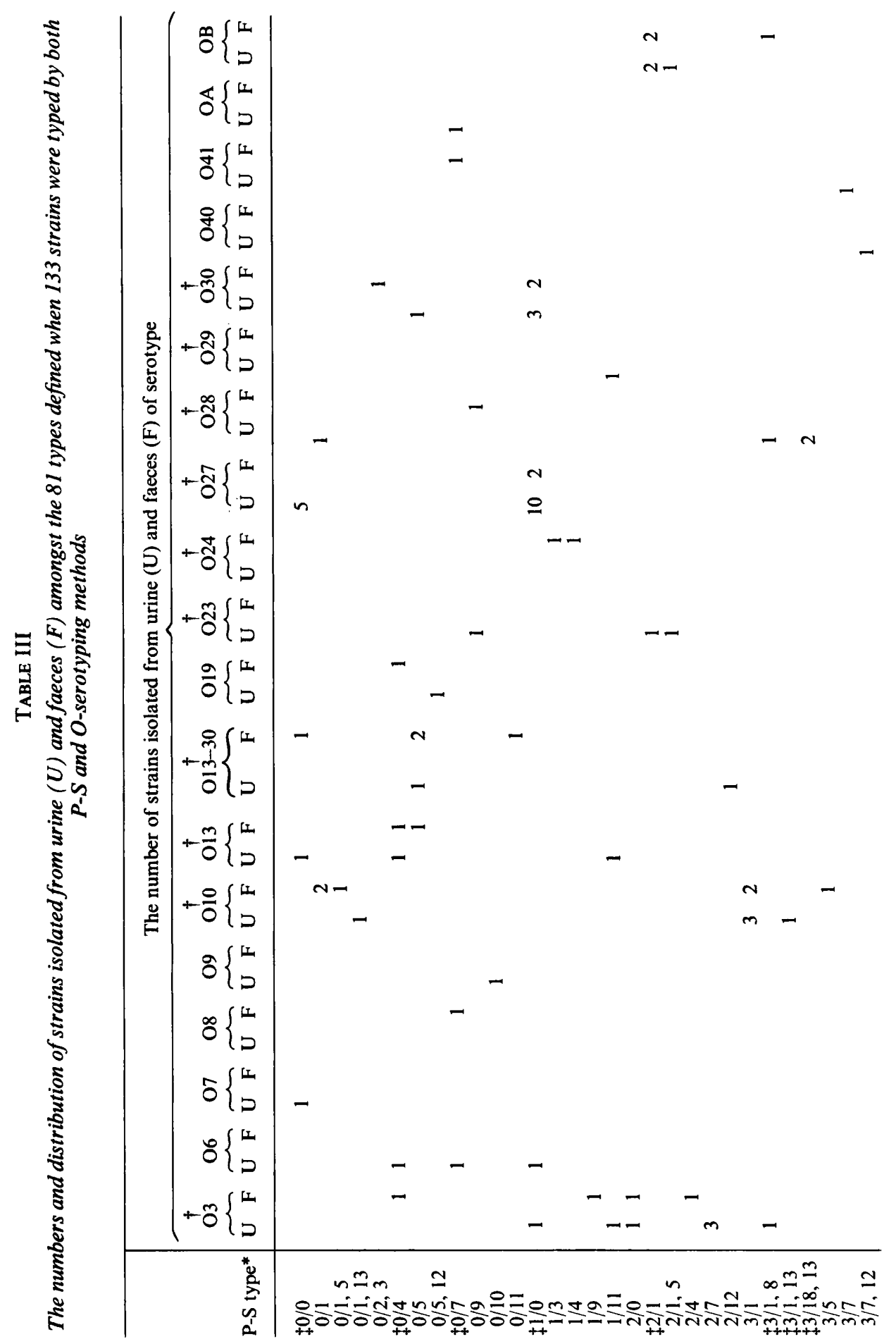




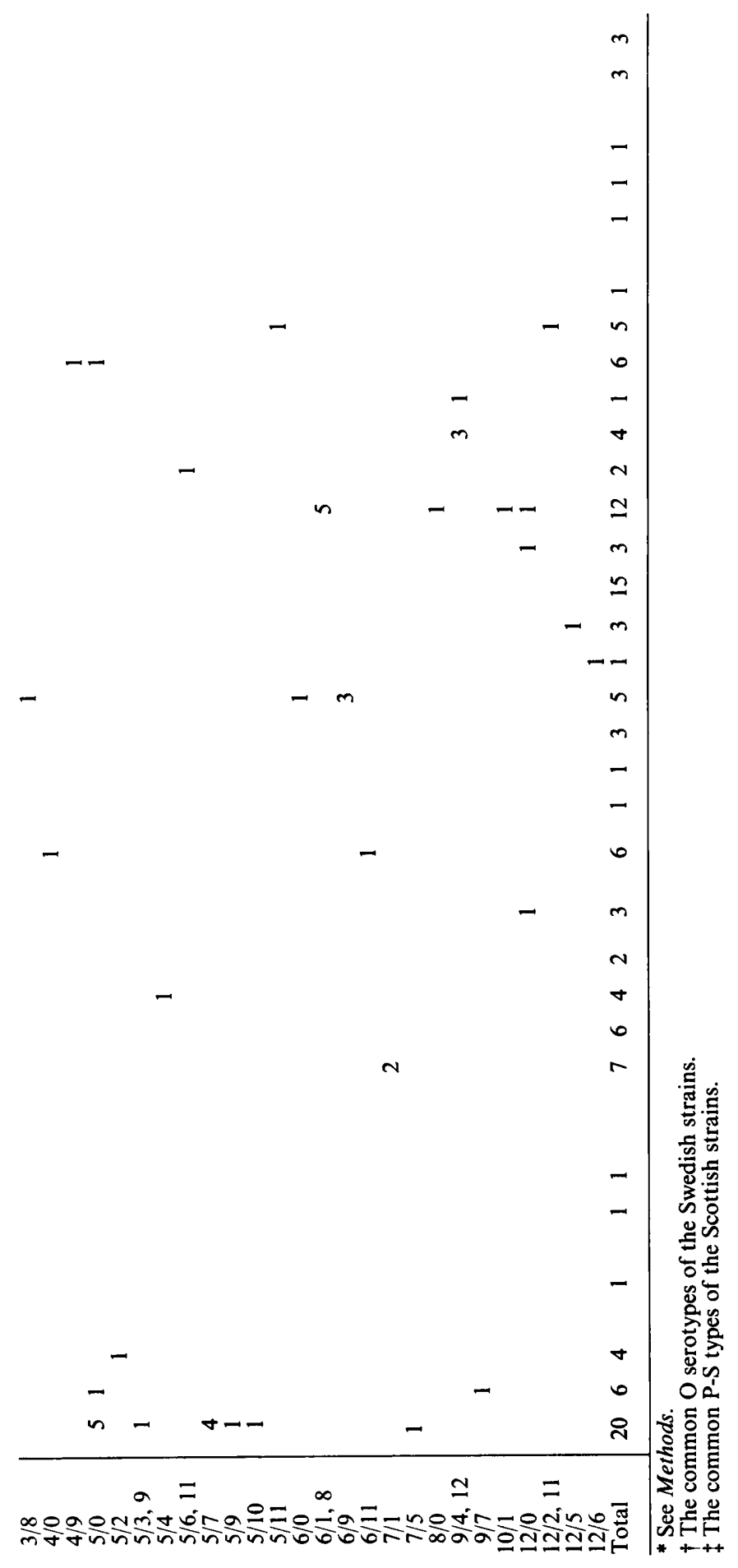


TABLE IV

The Dienes compatibility reactions of strains of the same $P-S$ type but different $O$ serotypes

\begin{tabular}{clc}
\hline $\begin{array}{c}\text { P-S types of strains } \\
\text { tested for Dienes } \\
\text { compatibility }\end{array}$ & $\begin{array}{c}\text { O-serotypes } \\
\text { of strains in test }\end{array}$ & $\begin{array}{c}\text { Number of } \\
\text { Dienes-compatibility } \\
\text { types found }\end{array}$ \\
\hline $0 / 1$ & O10, O28 & 2 \\
$0 / 4$ & O3, O6, O13, O19 & 2 \\
$0 / 5$ & O13, O13-30, O30 & 1 \\
$0 / 7$ & O6, O8, O41, OA & 1 \\
$0 / 9$ & O23, O28 & 1 \\
$1 / 0$ & O3, O6, O27, O30 & 4 \\
$1 / 11$ & O3, O13, O29 & 3 \\
$2 / 1$ & O23, OB & 1 \\
$2 / 1,5$ & O23, OB & 1 \\
$3 / 1,8$ & O3, OB & 2 \\
$5 / 0$ & O3, O30 & 1 \\
$12 / 0$ & O13-30, O27, O28 & 3 \\
\hline
\end{tabular}

The determinants of Dienes compatibility, according to Cunliffe and Krikler (1953), are $\mathrm{H}$ antigens. However, others have found a greater number of Dienes types than can be explained on the basis of differences in $\mathrm{H}$ antigenicity (Senior, 1977b) and serologically identical strains may be of different Dienes types (De Louvois, 1969). Skirrow (1969) showed that strains with the same $\mathrm{O}$ antigen but different $\mathrm{H}$ antigens could be of the same Dienes type. Our results confirm those of De Louvois (1969) and Skirrow (1969). We found no evidence to support the suggestion that the determinants of $\mathrm{O}$ antigenicity play any role as determinants of Dienes compatibility. Many examples were found of $\mathrm{O}$-antigenically distinct strains that belonged to the same Dienes compatibility group and O-antigenically identical strains that were incompatible with each other in a Dienes test.

Our results support the findings of Senior $(1977 b)$ that the determinants of Dienes compatibility are the proticine production and proticine sensitivity characters. Regardless of whether strains were of the same O serotype or not, if their P-S types were different they were incompatible. If their P-S types were identical most strains were compatible. A very small number of strains of the same P-S type were incompatible. This was reported by Senior (1977b) and is explained on the basis that there are differences between the P-S types of the incompatible strains but that the typing strains available at present cannot detect these differences.

The aim of this study was to investigate the suitability of combining different typing methods to provide a highly discriminating scheme for identifying particular types of Proteus. The scheme can be used for strains of $P$. mirabilis or $P$. vulgaris regardless of their origin. It is suggested that if the need is only to determine whether or not there is a common type amongst a small number of isolates, the rapid and simple Dienes typing method should be adequate. However, if a large number of strains have to be examined, Dienes typing of all combinations of strains becomes very complicated and $\mathrm{P}-\mathrm{S}$ typing or $\mathrm{O}$ serotyping methods would be more suitable. The finest discrimination between strains is given by combining P-S typing and $O$ serotyping. Strains that are of the same P-S type and O serotype may then, in some cases, be differentiated by Dienes typing. 
We are grateful to Dr R. M. Maskell and L. Pead of the Public Health Laboratory, St Mary's General Hospital, Portsmouth for the gift of strains. The technical assistance of Ms K. Larsson is gratefully acknowledged.

\section{REFERENCES}

Barry, G. T., Everhart, D. L., Abbott, V. and Graham, M. G. 1965. Preparation, properties and relationship of substances possessing colicine A activity obtained from the Enterobacteriaceae. Zentralblatt für Bakteriologie Parasitenkunde Infektions krankheiten und Hygiene, I. Abt. Orig., 196, 248-263.

BERGSTRÖM, T. 1972. Sex differences in childhood urinary tract infection. Archives of Diseases of Childhood, 47, 227-232.

Braude, A. I., Siemienski, J. ANd Shapiro, A. B. 1960. The role of bacterial urease in the pathogenesis of pyelonephritis. In Biology of pyelonephritis, edited by E. L. Quinn and E. H. Kass, Churchill Livingstone, London, pp. 69-88.

CunlifFe, A. C. AND KRIKLER, M. S. 1953. A cultural test for the presumptive serological identity of strains of Proteus vulgaris. Abstracts of 6th International Congress of Microbiology, Roma, 1, 861-862.

De Louvols, J. 1969. Serotyping and the Dienes reaction on Proteus mirabilis from hospital infections. Journal of Clinical Pathology, 22, 263-268.

Fairley, K. F., Carson, N.E., Gutch, R.C., Leighton, P., Grounds, A.D., Laird, E.C., McCallum, P.H.G., Sleeman, R.L. and O'Keefe, C.M. 1971. Site of infection in acute urinary tract infection in general practice. Lancet, $2,615$.

Goebel, W. F. AND BarRy, G. T. 1958. Colicine K. II. The preparation and properties of a substance having colicine K activity. Journal of Experimental Medicine, 107, 185-209.

Griffith, D. P., Musher, D. M. AND CAMPBell, J. W. 1973. Inhibition of bacterial urease. Investigative Urology, 11, 234-238.

Hallett, R. J., Pead, L. AND Maskell, R. 1976. Urinary infection in boys. A three year prospective study. Lancet, 2, 1107-1110.

Hutton, J. J. AND Goebel, W. F. 1962. The isolation of colicine V and a study of its immunological properties. Journal of General Physiology, 45 (Suppl.), 125-141.

KAShbur, I. M., GeORgE, R. H. AND AylifFe, G. A. J. 1974. Resistotyping of Proteus mirabilis and a comparison with other methods of typing. Journal of Clinical Pathology, 27, $572-577$.

KauffmanN, F. 1966. The Bacteriology of Enterobacteriaceae: collected studies, 3rd ed., Williams and Wilkins, Baltimore, p. 333.

LÁNYI, B. 1956. Serological typing of Proteus strains from infantile enteritis and other sources. Acta Microbiologica Academiae Scientiarum Hungaricae, 3, 417-428.

LARSSON, P., ANDERSSON, H.E. AND NoRLEN, B. 1978. Serotyping in epidemiological tracing of nosocomially acquired Proteus mirabilis in a geriatric ward. Infection 6, 105-110.

LARSSON, P. AND Olling, S. 1977. O antigen distribution and sensitivity to the bactericidal effect of normal human serum of Proteus strains from clinical specimens. Medical Microbiology and Immunology, 163, 77-82.

Penner, J. L. AND Hennessy, J. N. 1980. Separate O-grouping schemes for serotyping clinical isolates of Proteus vulgaris and Proteus mirabilis. Journal of Clinical Microbiology, 12, 304-309.

PERCH, B. 1948. On the serology of the Proteus group. Acta Pathologica et Microbiologica Scandinavica, 25, 703-714.

SChmidt, W. C. AND Jefreries, C. D. 1974. Bacteriophage typing of Proteus mirabilis, Proteus vulgaris and Proteus morganii. Applied Microbiology, 27, 47-53.

Senior, B. W. 1977a. Typing of Proteus strains by proticine production and sensitivity. Journal of Medical Microbiology, 10, 7-17.

SeNIOR, B. W. $1977 b$. The Dienes Phenomenon: Identification of the determinants of compatibility. Journal of General Microbiology, 102, 235-244.

SENIOR, B. W. 1979. The special affinity of particular types of Proteus mirabilis for the urinary tract. Journal of Medical Microbiology, 12, 1-8. 
Senior, B. W., Bradford, N. C. And Simpson, D. S. 1980. The ureases of Proteus strains in relation to virulence for the urinary tract. Journal of Medical Microbiology, 13, 507-512.

SkIRrow, M. B. 1969. The Dienes (mutual inhibition) test in the investigation of Proteus infections. Journal of Medical Microbiology, 2, 471-477.

TRACY, O. AND ThOMsON, E. J. 1972. An evaluation of three methods of typing organisms of the genus Proteus. Journal of Clinical Pathology, 25, 59-72.

Walkey, F. A., Judge, T. G., Thompson, J. AND SARKARI, N. B. 1967. Incidence of urinary infection in the elderly. Scottish Medical Journal, 12, 411-414. 